\title{
CORRIGENDUM
}

\section{Chemical methods for the production of graphenes}

Sungjin Park and Rodney S. Ruoff

Nature Nanotechnology 4, 217-224 (2009); published online: 29 March 2009; corrected after print: 21 March 2010.

In the version of this Review Article originally published, the unit for conductivity in the first line of Table 2 should have been $\mathrm{S} \mathrm{cm}{ }^{-1}$. This error has been corrected in the HTML and PDF versions of the text. 